\title{
The selective cyclooxygenase-1 inhibitor SC-560 suppresses cell proliferation and induces apoptosis in human hepatocellular carcinoma cells
}

\author{
NADIA LAMPIASI ${ }^{1 *}$, DANIELA FODERà $^{1 *}$, NATALE D'ALESSANDRO ${ }^{2}$, ANTONELLA CUSIMANO $^{3}$, \\ ANTONINA AZZOLINA ${ }^{1}$, CLAUDIO TRIPODO ${ }^{4}$, ADA MARIA FLORENA ${ }^{4}$, MARTA IDA MINERVINI ${ }^{5}$, \\ MONICA NOTARBARTOLO ${ }^{2}$, GIUSEPPE MONTALTO ${ }^{3}$ and MELCHIORRE CERVELLO ${ }^{1}$ \\ ${ }^{1}$ Istituto di Biomedicina e Immunologia Molecolare ‘Alberto Monroy', C.N.R.; ${ }^{2}$ Dipartimento di Scienze Farmacologiche, \\ ${ }^{3}$ Dipartimento di Medicina Clinica e delle Patologie Emergenti, ${ }_{4}^{4}$ Istituto di Anatomia e Istologia Patologica, \\ Università di Palermo; ${ }^{5}$ Istituto Mediterraneo Trapianti e Terapie, Palermo, Italy
}

Received July 29, 2005; Accepted August 29, 2005

\begin{abstract}
Two isoforms of cyclooxygenase (COX) are known, and to date most studies have implicated COX-2 in the development and progression of various human cancers. Increasing evidence suggests that COX-1 may also play a similar role. Indeed, we have recently observed that the dual COX-1/COX-2 inhibitor indomethacin induces apoptosis in human hepatocellular carcinoma (HCC) cell lines more effectively than the selective COX-2 inhibitors, possibly implicating COX-1 in HCC. In this study we investigated the expression of COX-1 in non-tumor and malignant human liver tissues, as well as the effects of the highly selective COX-1 inhibitor SC-560 on cell growth and apoptosis in human HCC cell lines. Expression of COX-1 was detected in nearly all the samples assayed, although with a high variability between non-tumoral (NT) and malignant tissues. The percentage of COX-1 positive cells was significantly higher in the NT tissues than in the tumors $(\mathrm{p}<0.0001)$. In well-differentiated HCC COX-1 expression was significantly higher than in the poorly-differentiated tissues $(\mathrm{p}<0.05)$. SC560 showed a dose- and time-dependent inhibitory effect on HCC cell growth. The combination of the COX-1 inhibitor with nimesulide and CAY10404, two selective COX-2 inhibitors, resulted in additive effects on cell growth inhibition. SC-560 also inhibited colony formation in soft agar and induced apoptosis in HCC cells in a dose-dependent manner. Moreover, SC-560 decreased the levels of the anti-apoptotic proteins
\end{abstract}

Correspondence to: Dr Melchiorre Cervello, Istituto di Biomedicina e Immunologia Molecolare 'Alberto Monroy', C.N.R., Via Ugo La Malfa 153, 90146 Palermo, Italy

E-mail: cervello@ibim.cnr.it

${ }^{*}$ Contributed equally

Key words: COX-1, COX-2, hepatocellular carcinoma, apoptosis, NSAIDs survivin and XIAP and activated caspase- 3 and -7 in a doseand time-dependent fashion. In conclusion, we report for the first time that the selective COX-1 inhibitor SC-560 exhibits anti-tumor and apoptotic effects in human HCC cells. Overall, our previous and present results suggest that both COX-1 and COX-2 inhibitors may have potential therapeutic implications in $\mathrm{HCC}$ patients.

\section{Introduction}

The incidence of hepatocellular carcinoma (HCC) has considerably increased in recent years, and HCC is now one of the ten most common cancers worldwide. Although both diagnostic and therapeutic measures for early-stage HCC have improved significantly, the HCC prognosis is still extremely poor. On the other hand, advanced HCC is a highly aggressive tumor with a very low rate, if any, of response to common therapies. This underlines the necessity to develop new strategies for both the prevention and treatment of HCC.

Chronic infection with hepatitis viruses and inflammation are risk factors for the development of HCC. However, the cellular mechanisms linking chronic inflammation to malignant transformation in this disorder are not clear. Several studies have demonstrated that treatment with non-steroidal antiinflammatory drugs (NSAIDs) can reduce the incidence and mortality of a wide range of tumors (1). These drugs inhibit the activity of cyclooxygenases (COX)-1 and -2. It is now wellestablished that the 'inducible' COX-2 enzyme is involved in the development and progression of colon, skin and breast cancers (2-4). Although less attention has been drawn to the potential role of the 'constitutive' COX-1 enzyme in carcinogenesis, recent evidence supports its implication in some types of tumors (5-9).

The role of the cyclooxygenases in hepatocellular carcinogenesis is still unclear. However, some studies have shown an increased expression of COX-2 in patients with different types of liver disease, suggesting its possible role, especially in the early stages of hepatocarcinogenesis (10-13). Results from our laboratory and others $(11,14,15)$ have shown that 
COX-2 inhibitors effectively inhibit the growth of HCC cells, whereas, to our knowledge there is still no experimental data on the role of COX-1 in HCC. However, in a previous study (15) we reported that the dual COX-1/COX-2 inhibitor indomethacin induces apoptosis in human $\mathrm{HCC}$ cell lines more effectively than selective COX-2 inhibitors, suggesting a possible role for COX-1 in human HCC. To further investigate this issue, in the present study we investigated the expression of COX-1 and -2 in both non-tumor and malignant liver tissues and HCC cell lines. In addition, the effects of COX-1 selective inhibitor (SC-560) (16) on HCC cell growth and apoptosis were also studied and compared with those of two selective COX-2 inhibitors, nimesulide and CAY10404, and of the dual inhibitor indomethacin.

\section{Materials and methods}

Tissue specimens. The study included 15 primary HCC patients with hepatitis virus-associated chronic liver disease (male 12, female 3; mean age 64, range 50-78 years). Nine patients only were considered for immunohistochemical analysis, and the remaining six for the reverse transcriptionpolymerase chain reaction analysis. All tissues in this study were surgical resection specimens. Paired tumor and surrounding non-tumor regions were analyzed in each patient. The disease was associated with the presence of serum HCV antibodies in 11 patients, and four were positive for HBsAg. Ten patients had an $\mathrm{HCC}>1.5 \mathrm{~cm}$ and $\leq 3.0 \mathrm{~cm}$, and five had $\mathrm{HCC}>3 \mathrm{~cm}$. All patients underwent surgery or liver transplantation at Division of Surgery at the University Medical School of Palermo or Istituto Mediterraneo Trapianti e Terapie. Informed consent was obtained from all patients. Three histologically normal liver tissues were used as controls.

For immunohistochemical analysis formalin-fixed, paraffin-embedded blocks were obtained from each specimen. Consecutive 4-6 $\mu \mathrm{m}$ tissue sections were cut from each block. HCC was histologically graded by two independent pathologists (A.M.F. and C.T.) and divided into 3 categories: well-differentiated (WD), moderately-differentiated (MD) or poorly-differentiated (PD).

Histopathological studies have suggested that HCC originate as relatively well-differentiated tumors and become progressively less differentiated at a later stage of their development $(17,18)$. To study the potential role of COX enzymes during tumor progression, and to avoid differences due to varying genetic backgrounds in the patients, we evaluated areas with different grades of differentiation in a single tumor mass. Therefore, comparison was restricted to the two areas with the greatest difference in differentiation grade (i.e. well-differentiated versus poorly-differentiated), while the intermediate area (MD) was not included in the analysis.

For RT-PCR studies of COX-1 and COX-2 gene expression, fresh tumor and non-tumor samples were collected during surgical resection. All samples were immediately frozen and stored at $-80^{\circ} \mathrm{C}$ until RNA extraction.

Histochemical staining. Specimens were de-waxed, hydrated and then heated in a microwave oven (3-4 cycles of $5 \mathrm{~min}$ each) in $10 \mathrm{mM}$ citrate buffer $(\mathrm{pH} \mathrm{6.0)}$, and then washed twice with PBS for $5 \mathrm{~min}$. All sections were incubated in 3\% hydrogen peroxide $(\mathrm{v} / \mathrm{v})$ in methanol for $5 \mathrm{~min}$ to inhibit endogenous peroxidase. Immunohistochemistry was performed by the streptavidin-biotin complex (StreptABC) using the following antibodies: rabbit polyclonal antibody against human COX-2 (Cayman Chemical, Ann Arbor, MI, USA) at a dilution of $1: 100$ for $2 \mathrm{~h}$ at $37^{\circ} \mathrm{C}$, and mouse monoclonal antibody against human COX-1 (Vector Laboratories, Burlingame, CA) at a dilution of 1:50 for $1 \mathrm{~h}$ at room temperature. Sections were then incubated for $30 \mathrm{~min}$ at room temperature with biotinylated anti-rabbit or anti-mouse immunoglobulin diluted in PBS, with streptavidin-biotin complex for $30 \mathrm{~min}$ at room temperature; the color was developed with 3-amino-9-ethyl-carbazole (AEC; Dako, Copenhagen, Denmark) for 5-10 $\mathrm{min}$ at room temperature and counterstained with Mayer hematoxylin for $3 \mathrm{~min}$. Immunohistochemical staining for COX-1 and COX-2 was semi-quantitatively evaluated by two independent observers (A.M.F., C.T.) using a scale of 0-5, according to both degree and intensity of staining, in which: 0 , negative; 1 , positive staining in $1-20 \%$ of cells; 2 , in $21-40 \%$; 3 , in $41-60 \%$; 4 , in $61-80 \%$; and $5, \geq 81 \%$.

Reagents and cell culture. Nimesulide, CAY10404, SC-560 and indomethacin were purchased from Cayman Chemical. All reagents were dissolved in dimethyl sulfoxide (DMSO). The HuH-6 and HA22T/VGH human HCC cells used in this study had a narrow range of passage number and were maintained as previously described (19).

Extraction of cellular RNA and reverse transcriptionpolymerase chain reaction $(R T-P C R)$. Total RNA was extracted from HCC tissues and cells using a TRIzol reagent (Invitrogen, Milan, Italy). RT-PCR was then performed using the Superscript One-step RT-PCR kit (Invitrogen). Quantification and equalization of the amount of cDNA was achieved using primers to amplify $\beta$-actin as an internal control. To amplify COX-1, COX-2 or $\beta$-actin fragments 20 , 25 and 30 cycles were used to determine whether DNA amplification was linear. All PCR products were analysed by electrophoresis on agarose gel and photographed. The sequences of primers used in the RT-PCR were as follows: COX-1, 5'-AGTACAGCTACGAGCAGTTCTTGTT-3' (sense) and 5'-GTCTCCATACAATTCCTCCAACTCT-3' (antisense); COX-2, 5'-GAGAAAACTGCTCAACACCG-3' (sense) and 5'-GCATACTCTGTTGTGTTCCC-3' (antisense); ß-actin, 5'-TCACCCACACTGTGCCCATCTACGA-3' (sense) and 5'-CAGCGGAACCGCTCATTGCCAATGG-3' (antisense).

Evaluation of cell growth by MTS assay. Cells (5x103/well) in complete medium, containing $1 \%(\mathrm{v} / \mathrm{v})$ fetal bovine serum (FBS), were distributed into each well of 96-well microtitre plates and then incubated overnight. At time 0 , the medium was replaced with fresh complete medium, containing $1 \%$ FBS, the agents were added and the cells were cultured for $72 \mathrm{~h}$. At the end of treatment with various concentrations of the inhibitors, MTS assay was performed using the CellTiter Aqueous OneSolution kit (Promega Corp., Madison, WI, 
USA) according to the manufacturer's instructions. Cytotoxicity was expressed as a percentage of the absorbance measured in the control cells. The inhibitory concentrations $50 \%\left(\mathrm{IC}_{50}\right)$ and $70 \%\left(\mathrm{IC}_{70}\right)$, defined as the doses of compound that inhibited respectively $50 \%$ and $70 \%$ of cell growth were interpolated from the dose-response curves obtained. Values were expressed as means \pm SD of three separate experiments, each in triplicate.

Soft agar assays. Cells $\left(2 \times 10^{4}\right)$ were resuspended in $1.5 \mathrm{ml}$ of $0.3 \%$ Bactoagar (Amersham Biosciences, Milan, Italy) in complete culture medium, containing $10 \%$ FBS and different concentrations of the drugs. This suspension was layered over $2 \mathrm{ml}$ of $0.6 \%$ agar in complete culture medium with or without drugs per well in 6-well plates. Every 3 days media were removed and replaced with $2 \mathrm{ml}$ of fresh complete culture medium containing or not the test drugs. The cells were incubated for 21 days and the colonies containing $>50$ cells were counted. Relative colony formation in soft agar was determined by the ratio of the average number of colonies in treated cells to the average number of colonies in cells treated with solvent (DMSO). All experiments were performed in duplicate and repeated 3 times.

Evaluation of cell cycle distribution, and apoptosis by flow cytometry and Hoechst 33258 staining. After $24 \mathrm{~h}$ of treatment, the percentage of cells in each phase of the cell cycle was determined as previously described (20). Apoptosis was determined by evaluating the percentage of events accumulated in the pre $\mathrm{G}_{0}-\mathrm{G}_{1}$ position and by studying phosphatidylserine exposure on cell surface as well as examining nuclear morphology after staining cells with Hoechst 33258 as reported elsewhere (20).

Assay of caspase activity. Cells (2x104/well) were treated with the test drugs during incubation in 96-well plates containing complete culture medium with $1 \%$ FBS. After $24 \mathrm{~h}$, the level of caspase activity in the cells was measured by the Apo$\mathrm{ONE}^{\mathrm{TM}}$ homogeneous caspase-3/7 assay (Promega) according to the manufacturer's instructions. Experiments were performed in duplicate and repeated twice.

Western blot analysis. At time of harvest, cell lysates were obtained and Western blotting performed as described previously (20), with primary antibodies raised against human COX-1 and COX-2 (Cayman Chemical), p53 (Santa Cruz Biotechnology, Santa Cruz, CA), survivin (Abcam Ltd., Cambridge, UK), XIAP (Cell Signaling Technologies, Inc., Beverly, MA) and mouse B-actin (Sigma-Aldrich Srl, Milan, Italy).

Statistical analysis. Data are expressed as median and range (min-max). The Mann-Whitney U test was used.

\section{Results}

Expression of COX-1 and COX-2 in human HCC tissues and cell lines. Expression of COX-1 and COX-2 in HCC and the surrounding non-tumor tissues was investigated by immunohistochemistry (n=9) (Fig. 1A) and semi-quantitative RT-PCR

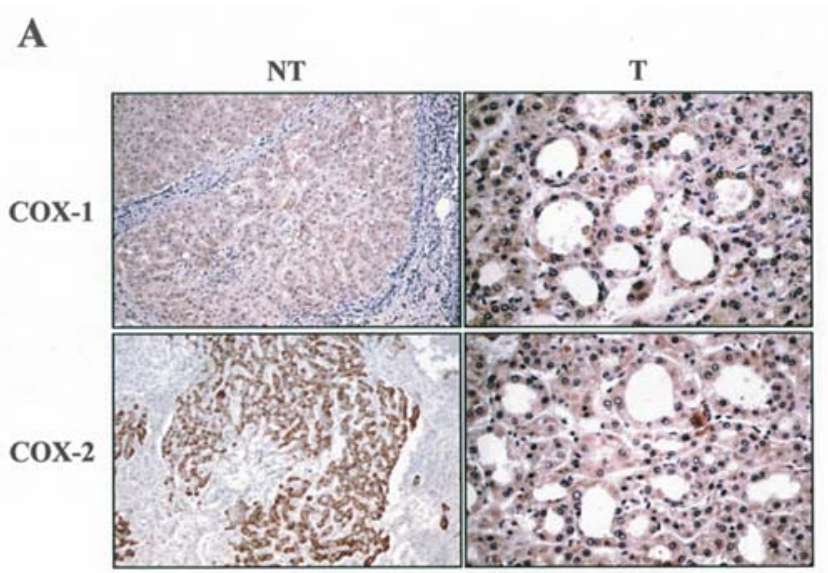

B

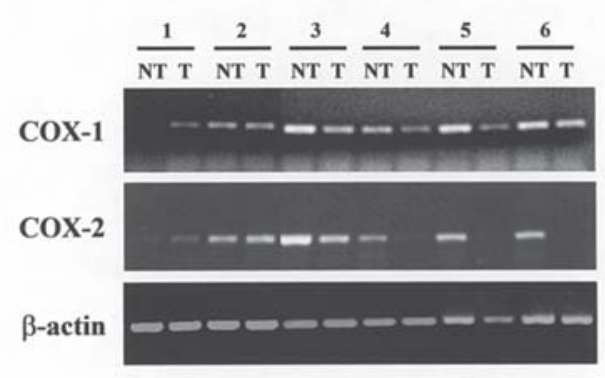

C

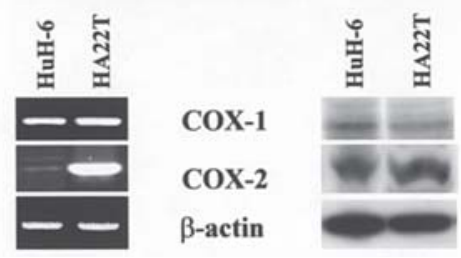

Figure 1. COX-1 and COX-2 protein and mRNA levels in human hepatocellular carcinoma tissues and cell lines. (A) COX-1 and COX-2 protein expression and cellular localization were determined by immunohistochemistry in cirrhotic tissues (NT) of two different patients, and in the same area of HCC tissue (T) of a single patient. (B) COX-1 and COX-2 mRNA levels were evaluated by RT-PCR in cirrhotic (NT) and HCC tissues (T). $\beta$-actin levels are shown as an internal control. The results shown are in the linear range of PCR amplification. The photographs shown represent two independent experiments. (C) COX-1 and COX-2 mRNA and protein levels evaluated by RT-PCR (left panel) and Western blotting (right panel). Identical amounts of protein $(25 \mu \mathrm{g})$ were used. The data shown represent three independent experiments with comparable outcomes.

$(n=6)$ (Fig. 1B) in patients with liver cirrhosis-associated HCC. Analysis showed the presence of COX-1 and COX-2 in all patients studied (Table I). COX-1 showed a cytoplasmic localization in the hepatocytes. A faint reaction was also observed in endothelial cells, whereas infiltrating inflammatory cells were not stained (data not shown). COX-1 expression was significantly higher in the non-tumor cirrhotic tissues (NT) than in the tumors except in one case [median $=4$ (range $=3-5$ ) versus $0.5(0-5) ; \mathrm{z}=3.8, \mathrm{p}<0.0001$ ] (Fig. 1A; Table I). Likewise, COX-2 expression was significantly higher in the NT tissues than in the tumors [5 (4-5) versus 1 $(0-5) ; \mathrm{z}=3.4, \mathrm{p}<0.0001$ ] (Table I) with a diffuse cytoplasmic localization in the NT hepatocytes and a cytoplasmic dotlike pattern in the tumor cells (Fig. 1A). Comparison between well-differentiated versus poorly-differentiated HCC showed that COX-1 and COX-2 expression was significantly higher in well-differentiated tumors [1 (0-5) versus $0(0-2)$ respectively, 
Table I. Scores representing immunohistochemical staining for COX-1 and COX-2 in human liver tissues.

\begin{tabular}{|c|c|c|c|c|c|c|}
\hline \multirow[b]{3}{*}{ No. } & \multirow[b]{3}{*}{ LC } & \multicolumn{2}{|c|}{ COX-1 } & \multicolumn{3}{|c|}{ COX-2 } \\
\hline & & \multicolumn{2}{|c|}{$\mathrm{HCC}$} & \multirow[b]{2}{*}{ LC } & \multicolumn{2}{|c|}{$\mathrm{HCC}$} \\
\hline & & WD & PD & & WD & PD \\
\hline 1 & 5 & 0 & 0 & 5 & 2 & 0 \\
\hline 2 & 5 & 1 & 0 & 5 & 4 & 1 \\
\hline 3 & 4 & 2 & 0 & 4 & 1 & 0 \\
\hline 4 & 5 & 2 & 0 & 4 & 4 & 0 \\
\hline 5 & 4 & 5 & 2 & 4 & 4 & 0 \\
\hline 6 & 3 & 1 & 0 & 5 & 4 & 0 \\
\hline 7 & 3 & 1 & 2 & 5 & 4 & 0 \\
\hline 8 & 5 & 0 & 0 & 4 & 3 & 0 \\
\hline 9 & 4 & 3 & 0 & 5 & 5 & 0 \\
\hline
\end{tabular}

Immunohistochemical staining for COX-1 and COX-2 was semiquantitatively evaluated by two independent observers using an arbitrary scale of $0-5$, according to both degree and intensity of staining, as reported in Materials and methods. LC, liver cirrhosis; HCC, hepatocellular carcinoma; WD, well-differentiated; PD, poorlydifferentiated.

$\mathrm{z}=2.0, \mathrm{p}<0.05$ for $\mathrm{COX}-1$; and $4(1-5)$ versus $0(0-1)$ respectively, $\mathrm{z}=3.7, \mathrm{p}<0.0001$ for COX-2] (Table I).

In four of the six patients analyzed the expression of COX-1 mRNA was higher in the surrounding non-tumor liver tissue than in the tumor (Fig. 1B). In one case COX-1 mRNA levels were higher in the tumor than in the NT tissue (Fig. 1B). COX-2 expression was up-regulated in two $\mathrm{T}$ and four NT samples, respectively (Fig. 1B). Moreover, a similar pattern was also noted between COX-1 and COX-2 expression in the two different areas (NT versus T) taken from each patient. In normal liver controls, COX-1 expression was weakly detected in one out of three samples, whereas COX-2 was completely absent in all three (data not shown).

COX-1 and COX-2 expression was studied also in the HuH-6 and HA22T/VGH human HCC cell lines by semiquantitative RT-PCR and Western blot. As shown in the left panel of Fig. 1C, COX-1 and COX-2 mRNAs were expressed by both HuH-6 and HA22T/VGH cell lines, with COX-2 expression especially prominent in $\mathrm{HA} 22 \mathrm{~T} / \mathrm{VGH}$ cells. In addition, Western blot analysis revealed that HuH-6 and HA22T/VHG cells express COX-1 and COX-2 proteins at equivalent levels (Fig. 1C, right panel).

Cell growth inhibition induced by COX inhibitors. We first assessed the effects of SC-560 (COX-1 inhibitor), nimesulide (COX-2 inhibitor), CAY10404 (COX-2 inhibitor), and indomethacin (dual COX inhibitor) on HCC cell growth by MTS assay. CAY10404 is a new selective inhibitor with a high $(>500,000)$ selectivity index $\left(\mathrm{IC}_{50} \mathrm{COX}-1 / \mathrm{IC}_{50} \mathrm{COX}-2\right)$ in favor of inhibition of COX-2, thus it has an $\mathrm{IC}_{50}$ value comparable to that of second generation selective COX-2 inhibitors, such as valdecoxib and etoricoxib (21). Combinations of SC-560 with nimesulide and CAY10404 were also tested. The doseresponse study showed that HuH-6 (Fig. 2A) and HA22T/ VGH (Fig. 2C) cells were responsive to all the drugs. After $72 \mathrm{~h}$ of exposure to SC-560, the $\mathrm{IC}_{50}$ values were 9 and $105 \mu \mathrm{M}$, and the $\mathrm{IC}_{70}$ values 30 and $193 \mu \mathrm{M}$, in HuH-6 and $\mathrm{HA} 22 \mathrm{~T} / \mathrm{VGH}$, respectively. Whereas, the $\mathrm{IC}_{50}$ values for nimesulide were 86 and $72 \mu \mathrm{M}$, and the $\mathrm{IC}_{70}$ values 148 and $200 \mu \mathrm{M}$, in HuH-6 and HA22T/VGH, respectively. The $\mathrm{IC}_{50}$ values for CAY10404 were 41 and $99 \mu \mathrm{M}$, and the $\mathrm{IC}_{70}$ values 63 and $>100 \mu \mathrm{M}$, in HuH-6 and HA22T/VGH, respectively. CAY10404 was tested up to $100 \mu \mathrm{M}$ that was the highest concentration that did not precipitate during the incubation period. The $\mathrm{IC}_{50}$ values for indomethacin were 46 and $88 \mu \mathrm{M}$, and the $\mathrm{IC}_{70}$ values 125 and $200 \mu \mathrm{M}$, in HuH-6 and HA22T/ VGH, respectively. The use of combinations of SC-560 with nimesulide and CAY10404, at concentrations equal to $25 \%$ and $50 \%$ of their $\mathrm{IC}_{50}$ values, resulted in considerably additive effects of cell growth inhibition both in HuH-6 and in HA22T/ VGH cells (Fig. 2B and D).

COX-1 inhibitor reduces anchorage-independent growth of HCC cells. To investigate whether SC-560 suppresses the transformed phenotype of HCC cells, the colony-forming abilities of HuH-6 cells in soft agar were examined. HuH-6 cells were grown in presence of increasing concentrations of SC-560 and after 3 weeks, the total colony number containing $>50$ cells was counted. As shown in Fig. 3, SC-560 inhibited anchorage-independent cell growth in a dose-dependent manner. We also tested the effect of nimesulide, CAY10404 and indomethacin on cell growth. Cells were more affected by treatment with SC-560, nimesulide or CAY10404 than by indomethacin (Fig. 3). In this assay the $\mathrm{IC}_{50}$ value for SC-560 was $<20 \mu \mathrm{M}$, whereas for nimesulide, CAY1040 and indomethacin, it was approximately $50 \mu \mathrm{M},<25 \mu \mathrm{M}$ and $100 \mu \mathrm{M}$, respectively.

SC-560 induces apoptosis in HCC cells. To investigate whether the anti-tumor effect of SC-560 could be due to its ability to induce apoptosis, we studied cell death in HCC cells treated with this compound for $48 \mathrm{~h}$ using flow cytometry analysis. SC-560 significantly increased the number of apoptotic cells expressed as the percentage of events accumulated in the $\mathrm{preG}_{0}-\mathrm{G}_{1}$ position (Fig. 4). In the same conditions, the effects with nimesulide, CAY10404 or indomethacin were less pronounced in both cell lines (Fig. 4). At the $\mathrm{IC}_{70}$ value, the effect of SC-560 was greater than nimesulide and CAY10404 in both cell lines, whereas was slightly lower than indomethacin only in HuH-6 cells (Fig. 4). Similar results were obtained assessing apoptosis through annexin $\mathrm{V}$ binding (data not shown).

Combinations of SC-560 with nimesulide, used at concentrations equal to $50 \%$ of their $\mathrm{IC}_{50}$ and $\mathrm{IC}_{70}$ values, resulted in additive effects on apoptosis induction in HuH-6 cells. In detail, concentration equal to $50 \%$ of $\mathrm{IC}_{50}$ value of SC-560 and nimesulide alone induced an increase in the apoptotic rate of 1.1 and 1.2 respectively, whereas their combination resulted in 1.7-fold increase as determined after $48 \mathrm{~h}$ by flow cytometry analysis of DNA stained with propidium iodide 
A

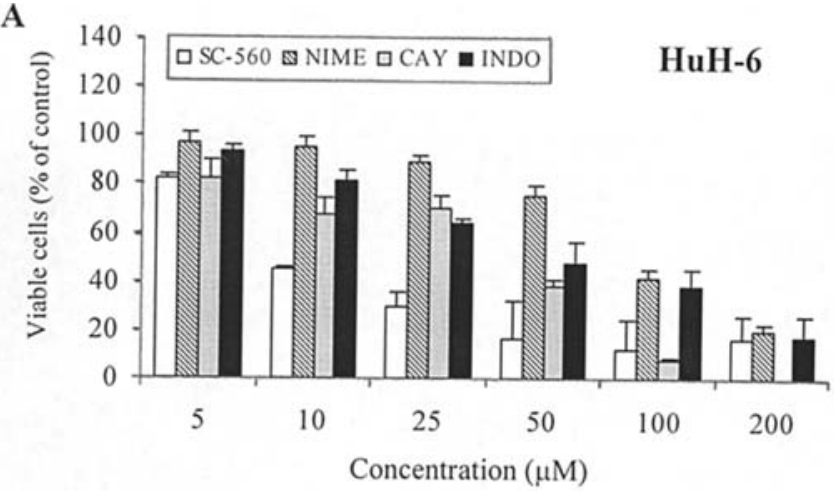

C

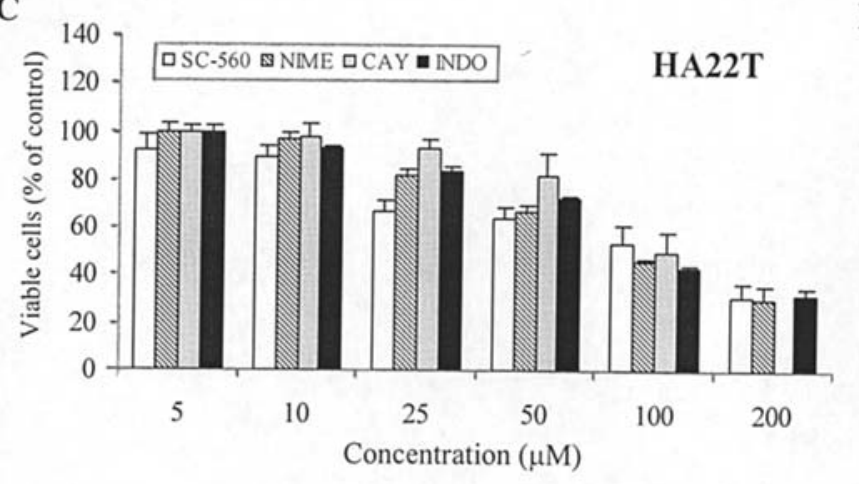

B

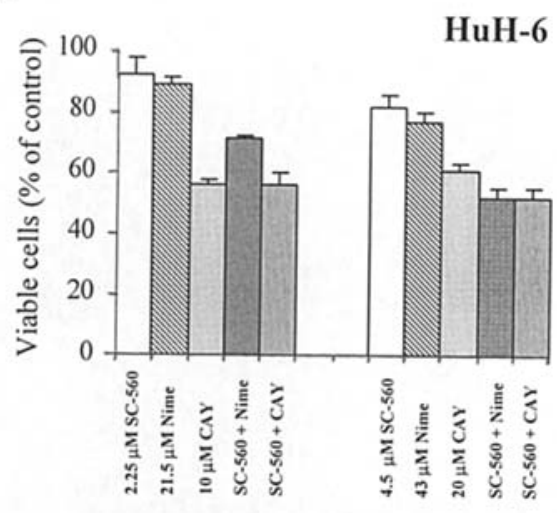

D

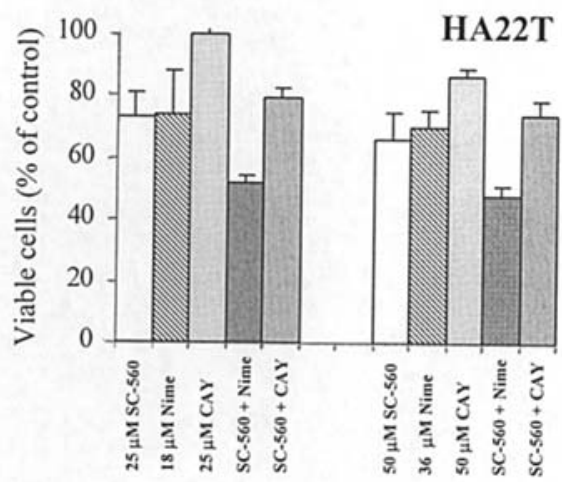

Figure 2. Growth inhibition induced by COX inhibitors. (A and B) HuH-6 and (C and D) HA22T/VGH cells were incubated in the presence of the indicated concentrations of the inhibitors alone (A and C) and their combinations (B and D) for $72 \mathrm{~h}$ and then cell viability was assessed by MTS assay. Data are expressed as the percentage of untreated cells and are the mean $\pm \mathrm{SD}$ of three separate experiments, each of which was performed in triplicate.

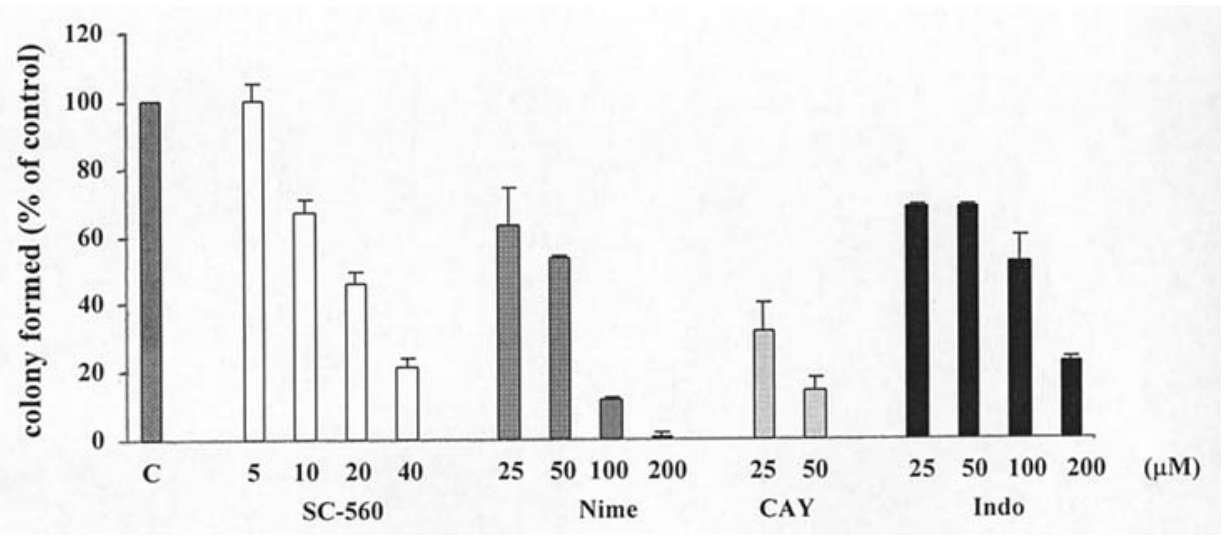

Figure 3. Effect of COX inhibitors on anchorage-independent growth of HCC cells. A representative experiment of HuH-6 cells grown in soft agar for 21 days. Cells were plated on soft agar in the absence or presence of the indicated concentrations of COX inhibitors. Data are expressed as percentage of colony in untreated cells $(\mathrm{C})$.

and by evaluating the percentage of events accumulated in the $\mathrm{preG}_{0}-\mathrm{G}_{1}$ position. At concentration equal to $50 \%$ of $\mathrm{IC}_{70}$ value SC-560 and nimesulide alone induced a 2 - and 1.5-fold increase in apoptotic rate, whereas their combination resulted in 3.2-fold induction.

Furthermore, apoptosis was evaluated in HuH- 6 cells by Hoechst 33258 staining. No signs of nuclear condensation and fragmentation were observed in control cells (Fig. 5C), whereas they became evident in the cells treated with SC-560
(Fig. 5D). We also examined the morphology of HCC cells by light microscopy. Treatment with SC-560 induced morphological changes in HA22T/VGH (data not shown) and HuH-6 cells (Fig. 5A and B), since the cells became sparse, rounded and detached from the culture dishes.

Effect of SC-560 on proteins regulating apoptosis in HCC cells. Separate experiments were carried out to investigate the potential effects of SC-560, nimesulide and indomethacin 
A

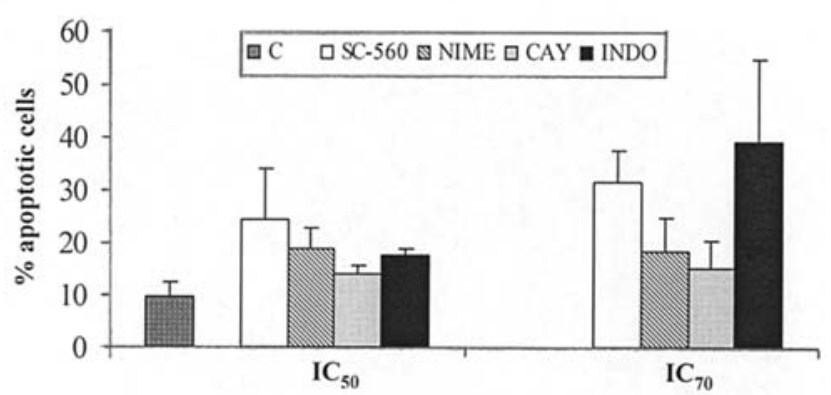

B

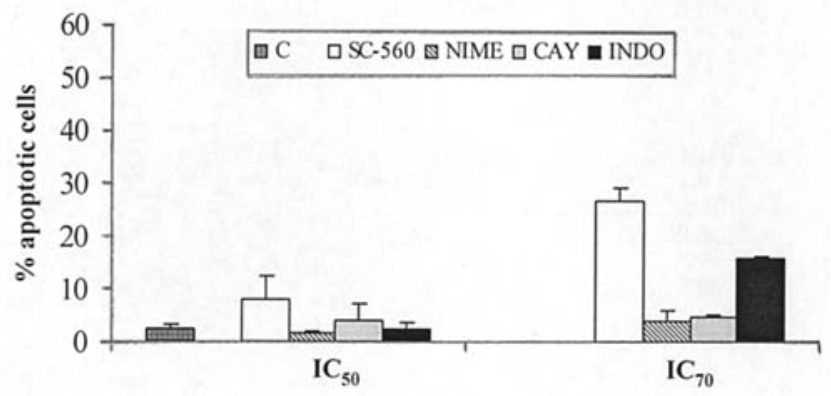

Figure 4. COX inhibitors increase apoptotic rate in HCC cells. HuH-6 (A) and $\mathrm{HA} 22 \mathrm{~T} / \mathrm{VGH}$ (B) cells were treated with $\mathrm{COX}$ inhibitors at concentrations corresponding to the $\mathrm{IC}_{50}$ and $\mathrm{IC}_{70}$ values, and cell death was determined after $48 \mathrm{~h}$ by flow cytometry analysis of DNA stained with propidium iodide and evaluating the percentage of events accumulated in the pre $_{0}-G_{1}$ position. Data are expressed as percentages of apoptotic cells and are the mean \pm SD of three separate experiments. C, untreated cells.
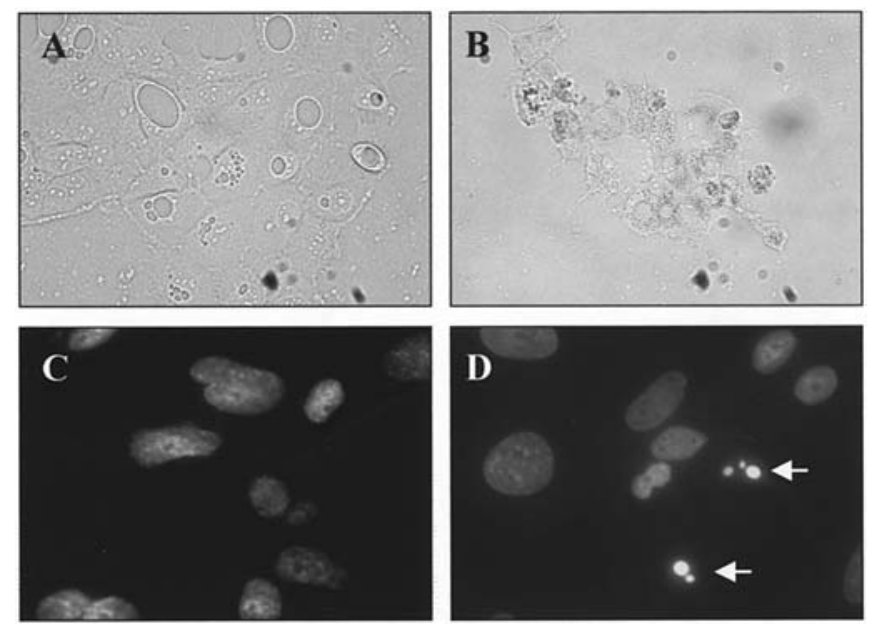

Figure 5. Morphological changes induced by SC-560 in HuH-6 cells. (A and B) bright field; (C and D) Hoechst 33258 staining. In (B) and (D) cells were exposed to $40 \mu \mathrm{M} \mathrm{SC}-560$ for $24 \mathrm{~h}$. The typically apoptotic appearance (fragmented and condensed nuclei) of cells treated with SC-560 are indicated by arrows.

on the expression of anti- and pro-apoptotic proteins in HCC cells. In HuH-6 cells, tumor suppressor p53 levels were unchanged (Fig. 6A), suggesting that the anti-tumor activity of all the drugs occurs in a p53-independent manner. In contrast, exposure to SC-560 for $24 \mathrm{~h}$ resulted in a dosedependent decrease in the two anti-apoptotic proteins XIAP and survivin (Fig. 6A). Nimesulide and indomethacin yielded
A

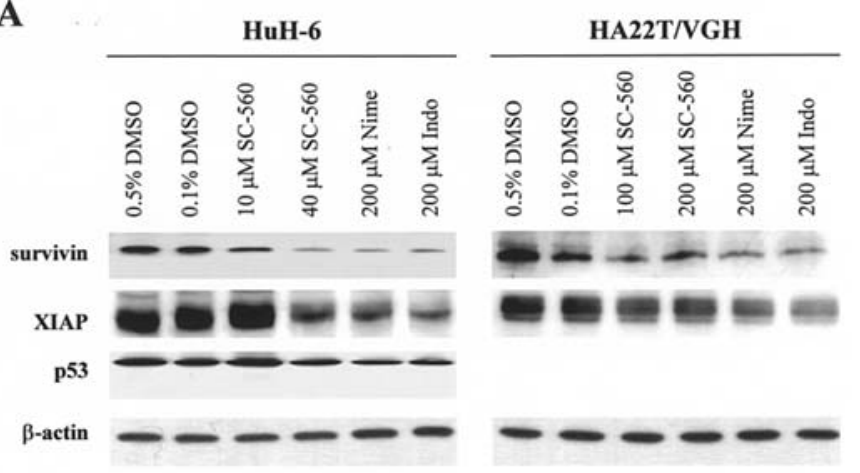

B

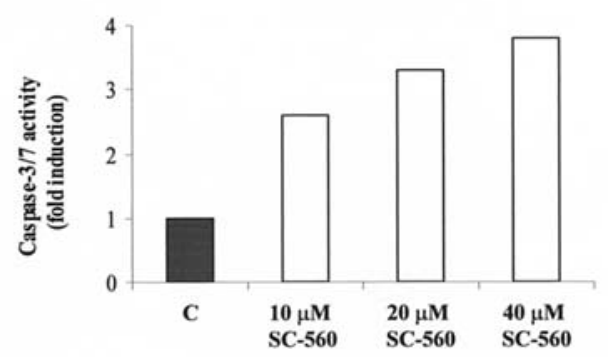

Figure 6. Reduction of survivin and XIAP protein levels and activation of caspase-3/7 after treatment of HCC cells with COX inhibitors. (A) HuH-6 and HA22T/VGH cells were treated with indicated concentrations of solvent alone (DMSO) or COX inhibitors for $24 \mathrm{~h}$ and then harvested. Identical amounts of protein $(25 \mu \mathrm{g})$ were used for Western blotting analysis. In HA22T/ VGH cells, p53 was barely detectable in the conditions used (data not shown). The data shown represent three independent experiments with comparable outcomes. (B) HuH-6 cells were incubated with the indicated concentrations of SC-560 for $24 \mathrm{~h}$, and caspase-3/7 activity was determined as described in Materials and methods. Data are expressed as a -fold increase of untreated cells $(\mathrm{C})$.

similar results (Fig. 6A). Equivalent results were also observed after $48 \mathrm{~h}$ of treatment (data not shown). In HA22T/VGH cells, SC-560 decreased survivin but not XIAP levels, whereas nimesulide and indomethacin decreased both survivin and XIAP (Fig. 6A). Expression of p53 in HA22T/VGH cells could not be detected.

Survivin and XIAP have been shown to inhibit apoptosis by binding to active caspase- 3 and caspase-7 (22). As survivin and XIAP levels decreased, the activity of caspase-3/7 increased in HuH-6 cells after exposure to SC-560 for $24 \mathrm{~h}$ (Fig. 6B).

\section{Discussion}

Several lines of evidence indicate that COX-2 is an important molecular target for anticancer therapies. Indeed, COX-2 has been shown to be involved in many processes of carcinogenesis, such as neoangiogenesis, inhibition of apoptosis, stimulation of cell growth as well as invasiveness and metastatic potential of tumor cells (1). We and others have shown that human HCC tissues and cells express COX-2 (10-15) and that targeting COX-2 with specific inhibitors may have potential therapeutic effects in HCC patients $(11,13,14,23-25)$. On the other hand, increasing evidence indicates that also COX-1 plays an essential role in skin and intestinal tumorigenesis (5-9). COX-1 is up-regulated in human breast (4), 
prostate (26), cervical (27) and ovarian cancers $(28,29)$. In addition, it has been shown that cooperation between COX-1 and COX-2 can be essential for intestinal polyp formation (8).

Since little attention has been paid to the possible role of COX-1 in HCC, in this study we analyzed COX-1 expression in $\mathrm{HCC}$ and the surrounding non-tumor tissues. On the whole, we found a higher COX-1 expression in the cirrhotic liver tissues surrounding HCC, than in the tumors. However, in two cases COX-1 was up-regulated in the tumor tissues compared to the adjacent non-tumoral cirrhotic tissues.

In HCC, it has been strongly suggested that as the tumor increases in size, foci of less-differentiated malignant tissues arise within the tumor mass and increase until they replace the well-differentiated tumor tissues. It has also been suggested that tumor growth depends on this phenomenon $(17,18)$. We found, in agreement with results reported by Koga et al (10), that COX-1 expression was higher in well-differentiated than in poorly-differentiated $\mathrm{HCC}$, suggesting that the presence of COX-1 might be involved in the early stages of tumor growth.

Our previous observations, showing the ability of the non-selective NSAID indomethacin to induce greater apoptotic rates than selective COX-2 inhibitors in HCC cells (15), prompted us to investigate the effects of the selective inhibition of COX-1 in HCC. In this study we used SC-560, which is 700 times more selective in inhibiting COX-1 than COX-2 (16), to treat two HCC cell lines, the HuH-6 and HA22T/ VGH cells, which express both COX isoforms. Consistent with previous reports on other tumor cell types (28-32), we found for the first time that treatment with the selective COX-1 inhibitor led to growth inhibition in a dose-dependent manner in HCC cells. The importance of COX-1 in the HCC cell growth was futher confirmed by the fact that SC-560 inhibited anchorage-independent growth of HuH-6 cells in soft agar, an in vitro marker for malignancy of cancer cells.

Furthermore, treatment of HCC cells with SC-560 triggered significant apoptotic effects; interestingly, at the level of nearly maximal effect of growth inhibition, i.e. using the $\mathrm{IC}_{70}$, the extent of apoptosis for SC-560 was slightly less than that of indomethacin and much greater than nimesulide and CAY10404, suggesting a possible independent survival role of each of the two COX isoforms in the cell lines.

On the other hand, cell growth assays indicated that the combination of the COX-1 and COX-2 inhibitors yielded additive results. Recently, the combination of COX-1 and COX-2 selective inhibitors was found to suppress polyp formation more effectively in the intestinal tumorigenesis of the Apc knockout mouse model (9). Since COX-1 and COX-2 catalyze identical reactions, it is possible that one COX isoform may compensate for the loss of the activity of the other. Inhibition of both isoforms may overcome such compensation and produce better results than those obtained with the single treatments.

We further investigated the possible mechanisms underlying the anti-tumor effects of SC-560. This compound decreased the levels of anti-apoptotic proteins survivin and XIAP in $\mathrm{HuH}-6$, and of survivin in HA22T/VGH in a dose- and timedependent manner. Survivin and XIAP have been shown to inhibit apoptosis by binding to active caspase- 3 and caspase- 7 (22); accordingly, we observed that SC-560 treatment of
HuH-6 cells resulted in an increase in the activity of such caspases. The ability of SC-560 to decrease survivin and XIAP expression, possibly explaining the induction of apoptosis by the compound, is a novel finding in HCC and suggests that inhibiting COX-1 might be an effective way to target these important downstream regulatory proteins.

However, it should take in consideration that increasing evidence suggests the involvement of molecular targets other than COX in the antiproliferative effects and induction of apoptosis of selective inhibitors (33). Moreover, the concentration of NSAIDs required to cause the biological response in cultured cells is usually much greater than that required to inhibit enzymatic activity. Therefore, the possibility that some of the effects observed in this study may be independent of their effects on COX activity cannot be ruled out. Investigation of the possible COX-independent effects of COX inhibitors in HCC cells is clearly warranted, and experiments evaluating the role of the mitogen-activated protein kinase and the phosphatidylinositol 3-kinase/Akt pathways in the antineoplastic effects of COX-1 as well as COX-2 selective inhibitors are currently underway.

\section{Acknowledgements}

We are grateful to Drs G. Carruba and L. Giannitrapani for helpful discussions, and Dr M. Soresi for his advice in statistical analysis. This work was supported by a grant from the Associazione Italiana per la Ricerca sul Cancro (AIRC), from MIUR-CNR Legge 449/97 2002-2003 and from the Italian Ministero dell'Università e della Ricerca Scientifica (ex $60 \%$ ) to G.M. and N.D.

\section{References}

1. Husain SS, Szabo IL and Tarnawski AS: NSAID inhibition of GI cancer growth: clinical implications and molecular mechanisms of action. Am J Gastroenterol 97: 542-553, 2002.

2. Sano H, Kawahito Y, Wilder RL, Hashiramoto A, Mukai S, Asai K, Kimura S, Kato H, Kondo M and Hla T: Expression of cyclooxygenase- 1 and cyclooxygenase- 2 in human colorectal cancer. Cancer Res 55: 3785-3789, 1995.

3. Brecher AR: The role of cyclooxygenase- 2 in the pathogenesis of skin cancer. J Drugs Dermatol 1: 44-47, 2002.

4. Hwang D, Scollard D, Byrne J and Levine E: Expression of cyclooxygenase- 1 and cyclooxygenase- 2 in human breast cancer. J Natl Cancer Inst 90: 455-460, 1998.

5. Chulada PC, Thompson MB, Mahler JF, Doyle CM, Gaul BW, Lee C, Tiano HF, Morham SG, Smithies O and Langenbach R: Genetic disruption of Ptgs-1, as well as Ptgs-2, reduces intestinal tumorigenesis in Min mice. Cancer Res 60: 4705-4708, 2000.

6. Kitamura T, Kawamori T, Uchiya N, Itoh M, Noda T, Matsuura M, Sugimura T and Wakabayashi K: Inhibitory effects of mofezolac, a cyclooxygenase-1 selective inhibitor, on intestinal carcinogenesis. Carcinogenesis 23: 1463-1466, 2002.

7. Tiano HF, Loftin CD, Akunda J, Lee CA, Spalding J, Sessoms A, Dunson DB, Rogan EG, Morham SG, Smart RC and Langenbach R: Deficiency of either cyclooxygenase (COX)-1 or COX-2 alters epidermal differentiation and reduces mouse skin tumorigenesis. Cancer Res 62: 3395-3401, 2002.

8. Takeda H, Sonoshita M, Oshima H, Sugihara K, Chulada PC, Langenbach R, Oshima M and Taketo MM: Cooperation of cyclooxygenase 1 and cyclooxygenase 2 in intestinal polyposis. Cancer Res 63: 4872-4877, 2003.

9. Kitamura T, Itoh M, Noda T, Matsuura M and Wakabayashi K: Combined effects of cyclooxygenase- 1 and cyclooxygenase- 2 selective inhibitors on intestinal tumorigenesis in adenomatous polyposis coli gene knockout mice. Int J Cancer 109: 576-580, 2004. 
10. Koga H, Sakisaka S, Ohishi M, Kawaguchi T, Taniguchi E, Sasatomi K, Harada M, Kusaba T, Tanaka M, Kimura R, Nakashima Y, Nakashima O, Kojiro M, Kurohiji T and Sata M: Expression of cyclooxygenase-2 in human hepatocellular carcinoma: relevance to tumor dedifferentiation. Hepatology 29: 688-689, 1999.

11. Bae SH, Jung ES, Park YM, Kim BS, Kim BK, Kim DG and Ryu WS: Expression of cyclooxygenase-2 (COX-2) in hepatocellular carcinoma and growth inhibition of HCC cells by a cyclooxygenase-2 inhibitor, NS-398. Clin Cancer Res 7: 1410-1418, 2001.

12. Rahman MA, Dhar DK, Yamaguchi E, Maruyama S, Sato T, Hayashi H, Ono T, Yamanoi A, Kohno H and Nagasue N: Coexpression of inducible nitric oxide synthase and COX-2 in hepatocellular carcinoma and surrounding liver: possible involvement of COX-2 in angiogenesis of hepatitis $\mathrm{C}$ viruspositive cases. Clin Cancer Res 7: 1325-1332, 2001.

13. Cervello M, Foderà D, Florena AM, Soresi M, Tripodo C, D'Alessandro N and Montalto G: Correlation between expression of cyclooxygenase- 2 and presence of inflammatory cells in human primary hepatocellular carcinoma: a possible role in tumor promotion and angiogenesis. World J Gastroenterol 11: 4638-4643, 2005

14. Hu KQ, Yu CH, Mineyama Y, McCracken JD, Hillebrand DJ and Hasan $\mathrm{M}$ : Inhibited proliferation of cyclooxygenase-2 expressing human HCC cells by NS-398, a selective COX-2 inhibitor. Int J Oncol 22: 757-763, 2003.

15. Foderà D, D'Alessandro N, Cusimano A, Poma P, Notarbartolo M, Lampiasi N, Montalto $\mathrm{G}$ and Cervello M: Induction of apoptosis and inhibition of cell growth in human hepatocellular carcinoma cells by COX-2 inhibitors. Ann NY Acad Sci 1028: 440-449, 2004.

16. Smith CJ, Zhang Y, Koboldt CM, Muhammad J, Zweifel BS, Shaffer A, Talley JJ, Masferrer JL, Seibert K and Isakson PC: Pharmacological analysis of cyclooxygenase-1 in inflammation. Proc Natl Acad Sci USA 95: 13313-13318, 1998.

17. Kenmochi K, Sugihara S and Kojiro M: Relationship of histologic grade of hepatocellular carcinoma (HCC) to tumor size, and demonstration of tumor cells of multiple different grades in single small HCC. Liver 7: 18-26, 1987.

18. Sugihara S, Nakashima O, Kojiro M, Majima Y, Tanaka M and Tanikawa K: The morphologic transition in hepatocellular carcinoma. A comparison of the individual histologic features disclosed by ultrasound-guided fine-needle biopsy with those of autopsy. Cancer 70: 1488-1492, 1992.

19. Cervello M, Notarbartolo M, Landino M, Cusimano A, Virruso L, Montalto G and D'Alessandro N: Downregulation of wild-type ß-catenin expression by interleukin 6 in human hepatocarcinoma HepG2 cells: a possible role in the growth-regulatory effects of the cytokine? Eur J Cancer 37: 512-519, 2001.

20. Cervello M, Giannitrapani L, La Rosa M, Notarbartolo M, Labbozzetta M, Poma P, Montalto G and D'Alessandro N: Induction of apoptosis by the proteasome inhibitor MG132 in human HCC cells: possible correlation with specific caspasedependent cleavage of $\beta$-catenin and inhibition of B-cateninmediated transactivation. Int J Mol Med 13: 741-748, 2004.
21. Mardini IA and Fitzgerald GA: Selective inhibitors of cyclooxygenase-2: a growing class of anti-inflammatory drugs. Mol Interv 1: 30-38, 2001.

22. La Casse EC, Baird S, Korneluk RG and MacKenzie AE: The inhibitors of apoptosis (IAPs) and their emerging role in cancer. Oncogene 17: 3247-3259, 1998

23. Kern MA, Schubert D and Sahi D: Proapoptotic and antiproliferative potential of selective cyclooxygenase-2 inhibitors in human liver tumor cells. Hepatology 36: 885-894, 2002.

24. Leng J, Han C, Demetris AJ, Michalopoulos GK and Wu T: Cyclooxygenase-2 promotes hepatocellular carcinoma cell growth through Akt activation: evidence for Akt inhibition in celecoxib-induced apoptosis. Hepatology 38: 756-768, 2003.

25. Cheng AS, Chan HL, Leung WK, Wong N, Johnson PJ and Sung JJ: Specific COX-2 inhibitor, NS-398, suppresses cellular proliferation and induces apoptosis in human hepatocellular carcinoma cells. Int J Oncol 23: 113-119, 2003.

26. Kirschenbaum A, Klausner AP, Lee R, Unger P, Yao S, Liu XH and Levine AC: Expression of cyclooxygenase-1 and cyclooxygenase-2 in the human prostate. Urology 56: 671-676, 2000 .

27. Sales KJ, Katz AA, Howard B, Soeters RP, Millar RP and Jabbour HN: Cyclooxygenase-1 is up-regulated in cervical carcinomas: autocrine/paracrine regulation of cyclooxygenase-2, prostaglandine receptors, and angiogenic factors by cyclooxygenase-1. Cancer Res 62: 424-432, 2002.

28. Gupta RA, Tejada LV, Tong BJ, Das SK, Morrow JD, Dey SK and Dubois RN: Cyclooxygenase-1 is overexpressed and promotes angiogenic growth factor production in ovarian cancer. Cancer Res 63: 906-911, 2003.

29. Daikoku T, Wang D, Tranguch S, Morrow JD, Orsulic S, Dubois RN and Dey KS: Cyclooxygenase-1 is a potential target for prevention and treatment of ovarian epithelial cancer. Cancer Res 65: 3735-3744, 2005.

30. Kundu N, Smyth MJ, Samsel L and Fulton AM: Cyclooxygenase inhibitors block cell growth, increase ceramide and inhibit cell cycle. Breast Cancer Res Treat 76: 57-64, 2002.

31. Bottone FG Jr, Martinez JM, Alston-Mills B and Eling TE: Gene modulation by Cox-1 and Cox-2 specific inhibitors in human colorectal carcinoma cancer cells. Carcinogenesis 25: 349-357, 2004.

32. Mohseni H, Zaslau S, McFadden D, Riggs DR, Jackson BJ and Kandzari S: COX-2 inhibition demonstrates potent antiproliferative effects on bladder cancer in vitro. J Surg Res 119: 138-142, 2004.

33. Tegeder I, Pfeilschifter J and Geisslinger G: Cyclooxygenaseindependent actions of cyclooxygenase inhibitors. FASEB J 15: 2057-2072, 2001. 